\title{
Impact of the Indonesian Throughflow on Agulhas leakage
}

\author{
D. Le Bars, H. A. Dijkstra, and W. P. M. De Ruijter \\ IMAU, Utrecht University, P.O. Box 80.005, 3508 TA Utrecht, the Netherlands
}

Correspondence to: D. Le Bars (d.lebars@uu.nl)

Received: 24 January 2013 - Published in Ocean Sci. Discuss.: 19 February 2013

Revised: 31 July 2013 - Accepted: 1 August 2013 - Published: 5 September 2013

\begin{abstract}
Using ocean models of different complexity we show that opening the Indonesian Passage between the $\mathrm{Pa}-$ cific and the Indian oceans increases the input of Indian Ocean water into the South Atlantic via the Agulhas leakage. In a strongly eddying global ocean model this response results from an increased Agulhas Current transport and a constant proportion of Agulhas retroflection south of Africa. The leakage increases through an increased frequency of ring shedding events. In an idealized two-layer and flat-bottom eddy resolving model, the proportion of the Agulhas Current transport that retroflects is (for a wide range of wind stress forcing) not affected by an opening of the Indonesian Passage. Using a comparison with a linear model and previous work on the retroflection problem, the result is explained as a balance between two mechanisms: decrease retroflection due to large-scale momentum balance and increase due to local barotropic/baroclinic instabilities.
\end{abstract}

\section{Introduction}

The Indonesian Passage forms an equatorial gateway between two major ocean basins which is a unique feature in the world ocean. Its existence allows for an input of Pacific water, the Indonesian Throughflow (ITF), that crosses the Indian Ocean and feeds its western boundary current, the Agulhas Current (AC), independently of Indian Ocean wind stress forcing. The ITF takes part in the so-called "warm water route" (Gordon, 1986) that brings thermocline water from the Pacific and Indian Oceans to the Atlantic Ocean through Agulhas leakage. This water also takes part on the Southern Hemisphere "supergyre" (Speich et al., 2007), feeds the Atlantic Meridional Overturning Circulation and may have an impact on its variability and strength (Biastoch et al., 2008a; Beal et al., 2011). One of the main issues of current research, and the topic of this paper, is the impact of the strength of the ITF on the Indian Ocean circulation and the Agulhas leakage.

The most direct model experiment to address this issue is to compare the global ocean circulation in the present-day world with that having a continental configuration in which the Indonesian Passage is (artificially) closed. Such model experiments have been carried out with both ocean-only models (Hirst and Godfrey, 1993; Lee et al., 2002) and global climate models (Schneider, 1998; Wajsowicz and Schneider, 2001; Song et al., 2007) using decadal-long simulations. In both classes of models, the presence of the ITF strengthens the South Equatorial Current and the AC, and the volume transport of the East Australian Current decreases. For example, this type of response of the Indo-Pacific ocean circulation was found both in the GFDL CM2.1 climate model (Song et al., 2007) and in the MITgcm ocean-only component (with a similar horizontal resolution of about $1^{\circ}$ ) as used in Lee et al. (2002).

In these model studies, not much attention was given to the impact of the ITF on the Agulhas leakage and the South Atlantic Ocean circulation. A crucial component of the IndoAtlantic connection is the retroflection of the AC. In ocean models with a horizontal resolution of only $1^{\circ}$, this retroflection is controlled by the wrong dynamical (i.e. viscous) processes. A much higher horizontal resolution is required to reach an inertial (or turbulent) retroflection regime (Dijkstra and de Ruijter, 2001a; Le Bars et al., 2012) which is thought to be more realistic regime. In addition to a more adequate representation of the boundary layer flow, the representation of mesoscale flows is also crucial to model a correct IndoAtlantic exchange (Biastoch et al., 2008b). 
From a theoretical point of view, two categories of processes are believed to play a role in determining the volume of Agulhas leakage. The large-scale forcing or "far field" (De Ruijter et al., 1999) sets the strength of the AC and the position of the Agulhas Return Current. A leakage of Agulhas water to the South Atlantic is possible because of the gap between the southern tip of the African continent $\left(37^{\circ} \mathrm{S}\right)$ and the southern limit of the subtropical gyre, materialized by the latitude of maximum westerlies, where the wind stress curl vanishes (around $48^{\circ} \mathrm{S}$ ). Secondly, local dynamics also plays an important role in the Agulhas retroflection. The inertia of the $\mathrm{AC}$ was shown to increase the proportion of retroflection (Ou and De Ruijter, 1986; Dijkstra and de Ruijter, 2001a; Le Bars et al., 2012). Although its role is not yet fully understood, the rectification of instabilities is also crucial for the mean leakage. Barotropic instabilities were shown to decrease the degree of retroflection (Dijkstra and De Ruijter, 2001b) but mixed barotropic/baroclinic instabilities may lead to a significant increase of the retroflection (Le Bars et al., 2012).

The Indonesian Throughflow is also part of the large-scale forcing of the Agulhas System. The inflow of water increases the strength of the AC but simultaneously water has to return south of Tasmania. In this case Hirst and Godfrey (1993) showed that potential vorticity constraints direct the flow zonally in the South Atlantic from Africa to South America. Through the input of negative vorticity at the coast there can be a flow southward which next is able to return eastward at the latitude of south Tasmania. In this case we would expect a decreased degree of retroflection with the increase of the ITF. However the situation is more complex because the Indonesian Throughflow - by strengthening the AC - also strengthens nonlinear processes south of Africa that are expected to increase the degree of retroflection. How these processes combine and impact the volume of Agulhas leakage will be analyzed in detail here.

The possible effect of the ITF on the Agulhas leakage will be analyzed using two $75 \mathrm{yr}$-long simulations with the strongly eddying version (with a $0.1^{\circ}$ horizontal resolution) of the Parallel Ocean Program (POP). In both simulations (closed vs open Indonesian Passage), the wind stress is the same and there is no restoring of the surface salinities. These model simulations therefore provide new insights on the dynamics of the Agulhas retroflection and the effect of the presence of the ITF on the Agulhas leakage in an inertial to turbulent retroflection regime. Results from simulations with a two-layer shallow-water model in an idealized basin geometry, allowing for more detailed sensitivity studies, are subsequently used to interpret the POP results. To understand better the physics of the previous two models, a linear model is also used to investigate the importance of nonlinear processes in the connection between the ITF and the Agulhas leakage. Its results are derived and discussed in Appendix A.

In Sect. 2 we describe the POP model simulations and provide an overview of the idealized shallow-water model used. In Sect. 3 we assess the strengths and weaknesses of POP for the simulation of the Agulhas retroflection and Agulhas leakage by comparing the model simulated (with realistic bathymetry) sea surface height field to satellite altimetry data. Main results on the impact of the ITF on the western Pacific, on the Indian Ocean and on the Agulhas retroflection are presented in Sect. 4 and further analyzed using the idealized shallow-water model in Sect. 5. A summary and discussion of the results follows in Sect. 6 .

\section{Model simulations}

Two numerical models are used in this paper. A global ocean model (POP) and a regional, idealized shallow-water model (HIM).

\subsection{POP configuration}

The global ocean simulations analyzed here were performed using the Parallel Ocean Program (POP, Dukowicz and Smith, 1994) developed at Los Alamos National Laboratory. The configuration is based on that used by Maltrud et al. (2010), with an average $0.1^{\circ}$ horizontal resolution and 42 vertical levels, allowing for a maximum depth of $6000 \mathrm{~m}$. The atmospheric state used to force the model is based on the repeat annual cycle (normal-year) Coordinated Ocean Reference Experiment $\left(\mathrm{CORE}^{1}\right)$ forcing dataset (Large and Yeager, 2004), with 6-hourly forcing averaged to monthly. Wind stress is computed offline using the Hurrell sea surface temperature (SST) climatology (Hurrell et al., 2008) and standard bulk formulae; evaporation and sensible heat flux were calculated online also using bulk formulae and the model predicted SST. Precipitation was also taken from the CORE forcing dataset. Sea-ice cover was prescribed based on the $-1.8^{\circ} \mathrm{C}$ isoline of the SST climatology, with both temperature and salinity restored on a timescale of 30 days under diagnosed climatological sea-ice.

As initial conditions we used the final state of a $75 \mathrm{yr}$ spin-up simulation described in Maltrud et al. (2010) using restoring conditions for salinity. The freshwater flux was diagnosed during the last five years of the spin-up simulation and the simulations we present in this paper use this diagnosed freshwater flux. This makes the ocean circulation free to adapt to changes in continental geometry, i.e. here the closing of the Indonesian Passage. Using this model we did a control simulation (POP_CTRL) with realistic bathymetry and another one (POP_NoITF) on which the Indonesian Passage was closed by small land bridges. Both POP simulations were continued under the same surface forcing for $75 \mathrm{yr}$, up to model year 150 .

\footnotetext{
${ }^{1}$ see http://www.clivar.org/organization/wgomd/core
} 
Table 1. Relevant parameters of the idealized experiments used for both open ITF (HIM_CTRL) and closed ITF (HIM_NoITF) cases.

\begin{tabular}{lrrrrr}
\hline Model & $\begin{array}{r}\text { Horizontal } \\
\text { resolution }\end{array}$ & $\begin{array}{r}\text { Viscosity } \\
\left(\mathrm{m}^{2} \mathrm{~s}^{-1}\right)\end{array}$ & $\begin{array}{r}\text { Number of } \\
\text { layers }\end{array}$ & $\begin{array}{r}\text { Density } \\
\left(\mathrm{kg} \mathrm{m}^{-3}\right)\end{array}$ & $\begin{array}{r}\text { Equilibrium thickness of } \\
\text { the layers }(m)\end{array}$ \\
\hline HIM & $0.1^{\circ}$ & 500 & 2 & 1030 & 1000 \\
& & & & 1035 & 2000 \\
\hline
\end{tabular}

Table 2. Mean transport (in Sv) across different sections of POP_CTRL and POP_NoITF rounded to integer values. The standard deviation is given between brackets. Note that the numbers are rounded to $1 \mathrm{~Sv}$.

\begin{tabular}{lrrrrrrrrrr}
\hline Section & ITF & EAC & TL & SEMC & MC & AC & AL & NBC & BC & $\begin{array}{r}\text { \# Agulhas } \\
\text { eddies per year }\end{array}$ \\
\hline POP_CTRL & $15(8)$ & $39(17)$ & $9(4)$ & $19(13)$ & $17(6)$ & $92(20)$ & $21(13)$ & $24(4)$ & $37(12)$ & $3.6(1.0)$ \\
POP_NoITF & $0(0)$ & $52(16)$ & $12(3)$ & $17(7)$ & $2(4)$ & $82(15)$ & $17(9)$ & $23(4)$ & $34(15)$ & $2.9(0.8)$ \\
Difference & $+15(+8)$ & $-13(+1)$ & $-2(+1)$ & $+3(+6)$ & $+15(+2)$ & $+10(+5)$ & $+3(+4)$ & $+1(0)$ & $+3(-3)$ & $+0.7(+0.2)$ \\
\hline
\end{tabular}

\subsection{HIM configuration}

To test dynamical mechanisms and help the interpretation of the POP simulations, we use an idealized configuration of the Hallberg Isopycnal Model (HIM, Hallberg (1997)). It uses a time-splitting scheme to solve the hydrostatic primitive equations in spherical coordinates on an Arakawa Cgrid. The model domain (Fig. 1) and the boundary conditions are similar to that used in Le Bars et al. (2012). The domain is centered on the Indian Ocean with the African continent and Madagascar in the western part and the Australian continent in the eastern part. There are 3 basins in this setup and we will call them Atlantic Ocean, Indian Ocean and Pacific Ocean even though the sizes of the Atlantic and Pacific basins are much smaller than in reality. This setup allows for water to go from the Pacific to the Indian Ocean.

We use zonal periodic boundary conditions between $60^{\circ} \mathrm{S}$ and $55^{\circ} \mathrm{S}$ to allow an Antarctic Circumpolar Current to develop. To reduce its intensity we have added a ridge at $130^{\circ} \mathrm{E}$; the longitudinal extent of this ridge is $1^{\circ}$ and its height is fixed to $2500 \mathrm{~m}$. The rest of the domain has a flat bottom. We use a horizontal resolution of $0.1^{\circ}$ and 2 vertical layers. Lateral friction is parameterized with a Laplacian horizontal eddy viscosity with a constant background value of $500 \mathrm{~m}^{2} \mathrm{~s}^{-1}$ and a Smagorinsky coefficient of 0.15 . We apply no-slip lateral boundary conditions and the model is forced by a steady zonal wind stress (Fig. 1) of the form:

$\tau^{\phi}(\theta)=-\tau_{0} \sin \left(\alpha\left(\theta-\theta_{0}\right)\right)$,

where $\theta$ is the latitude and with $\theta_{0}=32^{\circ} \mathrm{S}$ and $\alpha=\pi / 32$. The wind-stress pattern is fixed but its amplitude is taken as control parameter and ranges from $0.05 \mathrm{~N} \mathrm{~m}^{-2}$ to $0.3 \mathrm{~N} \mathrm{~m}^{-2}$. For each amplitude of the wind stress we run the model to reach a statistical equilibrium and for analysis we take an average of five years of each experiment. A set of 6 experiments under different wind stresses is performed for a control experiment (HIM_CTRL) and we compare the results with a set of simulations in which the Indonesian Passage is closed (HIM_NoITF); see Table 1 for a summary of the parameters for the two cases.

\section{POP model - data comparison}

To assess the skills of the POP model in simulating the Agulhas retroflection, we compare the sea surface height (SSH) simulation results for the case POP_CTRL with satellite altimeter data produced by Ssalto/Duacs and distributed by AVISO, with support from CNES (http://www.aviso. oceanobs.com/duacs/). The dataset of the dynamic topography for the altimeter results is provided on $\mathrm{a} \frac{1}{3}^{\circ} \times \frac{1}{3}^{\circ}$ grid.

\subsection{Volume transports and Agulhas leakage}

The time mean dynamic topography deduced from the satellite observation and from POP_CTRL for the Indian Ocean and South Atlantic Ocean is plotted in Fig. 2. The average transport of the main currents and strait transports expected to be impacted by the ITF are computed over a $40 \mathrm{yr}$ period for both POP_CTRL and POP_NoITF and are given in Table 2. In POP_CTRL the transport of the ITF is $15 \mathrm{~Sv}$ which is close to the estimation based on observations by Sprintall et al. (2009). The Mozambique Channel transport is $17 \mathrm{~Sv}$ also close to the $16.7 \mathrm{~Sv}$ observed by Ridderinkhof et al. (2010). The transport of the $\mathrm{AC}$ at $32^{\circ} \mathrm{S}$ is $92 \mathrm{~Sv}$, much larger than the $69.7 \mathrm{~Sv} \pm 4.3 \mathrm{~Sv}$ observed by Bryden et al. (2005). However, Bryden et al. (2005) only registered the current strength over a period of 8 months, which is not enough given the important annual and inter-annual variability; the yearly averaged transport in POP_CTRL varies between $74 \mathrm{~Sv}$ and $104 \mathrm{~Sv}$. Another possible explanation for the discrepancy in $\mathrm{AC}$ transport values is the relatively strong recirculation in the southwest Indian Ocean (see Fig. 3a-b) that can locally break the Sverdrup balance and increase the transport. 


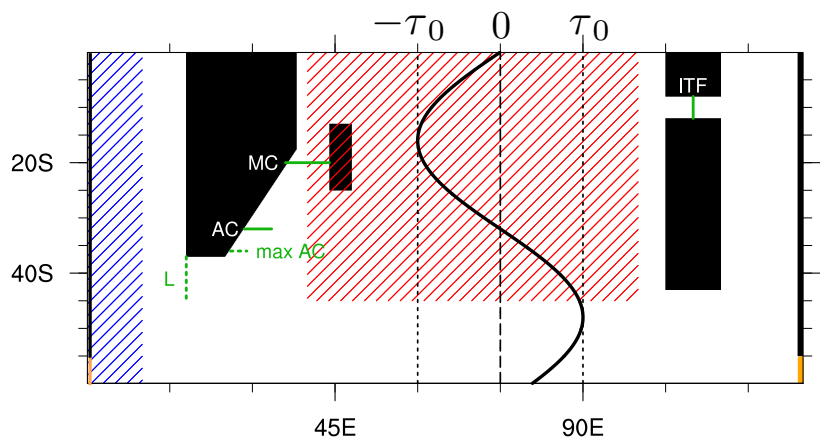

Fig. 1. Domain of the idealized model HIM with continents (black), ridge (orange), profile of wind stress forcing and important sections (ITF: Indonesian Throughflow, MC: Mozambique Channel, AC: Agulhas Current, L: Leakage). Also indicated is the regions where tracer concentration is fixed to 1 (red hatching) and 0 (blue hatching). The passive tracer is used to compute the leakage, it is initialized to zero in the white regions but is free to evolve in time.

Computing Agulhas leakage is difficult because of the highly turbulent nature of the flow south of Africa. Lagrangian tracers (Biastoch et al., 2008b; Van Sebille et al., 2009a) or passive Eulerian tracer (Le Bars et al., 2012) are required to compute an accurate time series. Unfortunately in these methods the tracers need either to be advected online or offline but using high frequency temporal output (at most a few days), which was not possible with the POP simulations. Another method is to use thresholds of temperature and salinity to separate Indian Ocean waters from its surroundings (Rouault et al., 2009; van Sebille et al., 2010). However, if the temperature and salinity of the South Indian Ocean change, which is the case for an opening of the Indonesian Passage, it introduces a bias in the computation and hence this method is not suited for the purpose of our study.

As we will see later (Fig. 7), the path of the Agulhas eddies does not change when the Indonesian Passage opens. For this reason, we choose here to compute the surface Eulerian volume flux across a fixed section that includes the direct eddy path and the Benguela Current (see Fig. 2). The value thus computed is $21 \mathrm{~Sv}$ (Table 2). This is higher than the estimation of Richardson (2007) who found $15 \mathrm{~Sv}$ using observations from subsurface floats and surface drifters. The higher value that we obtain here is probably due to the method we use, some of the flow that we measure is Atlantic water and not Agulhas leakage. However our main concern here is not to have a precise measure of the leakage in the control experiment but to measure the difference with the case without ITF. Therefore this method is based on the reasonable assumption that the ITF impact on the volume transport of Atlantic water at the section we choose is small compared to the ITF impact on the Agulhas leakage.

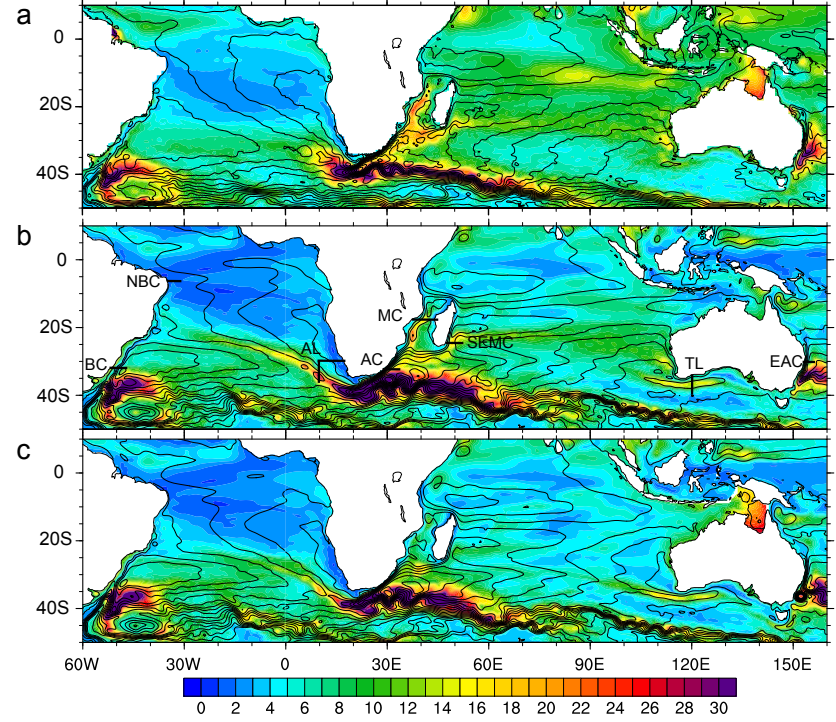

Fig. 2. Contour of mean dynamic topography and standard deviation (colors, in $\mathrm{cm}$ ) from (a) altimetry data, (b POP_CTRL and (c) POP_noITF. Sections used for Table 2 are also shown here (EAC: East Australian Current at $30^{\circ} \mathrm{S}$, TL: Tasman Leakage, NBC: North Brazil Current at $6^{\circ} \mathrm{S}$, SEMC: South East Madagascar Current, BC: Brazil Current at $32^{\circ} \mathrm{S}$, AL: Agulhas leakage, AC: Agulhas Current at $32^{\circ} \mathrm{S}, \mathrm{MC}$ : Mozambique Channel).

\subsection{Agulhas retroflection}

To assess the performance of POP_CTRL in modeling the $\mathrm{AC}$ retroflection we compare the average and standard deviation of the SSH (using the last $20 \mathrm{yr}$ of the model simulation) with satellite altimetry (Fig. 3a-b). The model adequately simulates a strong $\mathrm{AC}$, its retroflection/recirculation south of Africa and the meandering Agulhas Return Current (ARC). The regions of high SSH variability in the Mozambique Channel, the area southeast of Madagascar and at the $\mathrm{AC}$ retroflection are also captured by the model. However, as already noticed by Maltrud and McClean (2005) in a similar POP simulation, the area of retroflection is broader and the variability is higher than observations in this region. In addition, the path of the eddies is very regular, leading to a unique well defined eddy corridor while in the satellite observations three dominant paths are found (Dencausse et al., 2010a).

To further analyze these differences between model and observations, we computed the retroflection position from satellite dynamic topography and from the model sea surface height (Fig. 4a-b). The method used is the same as Dencausse et al. (2010b): we choose a SSH contour representative of the AC and ARC cores and look for its western most point for each output file. Note that the output frequency is weekly for satellite and monthly for model data. The average retroflection position deduced from satellite data is localized at $18^{\circ} \mathrm{E}$, after the current has left the coast and forms a free jet. In the model, the highest probability of retroflection is 

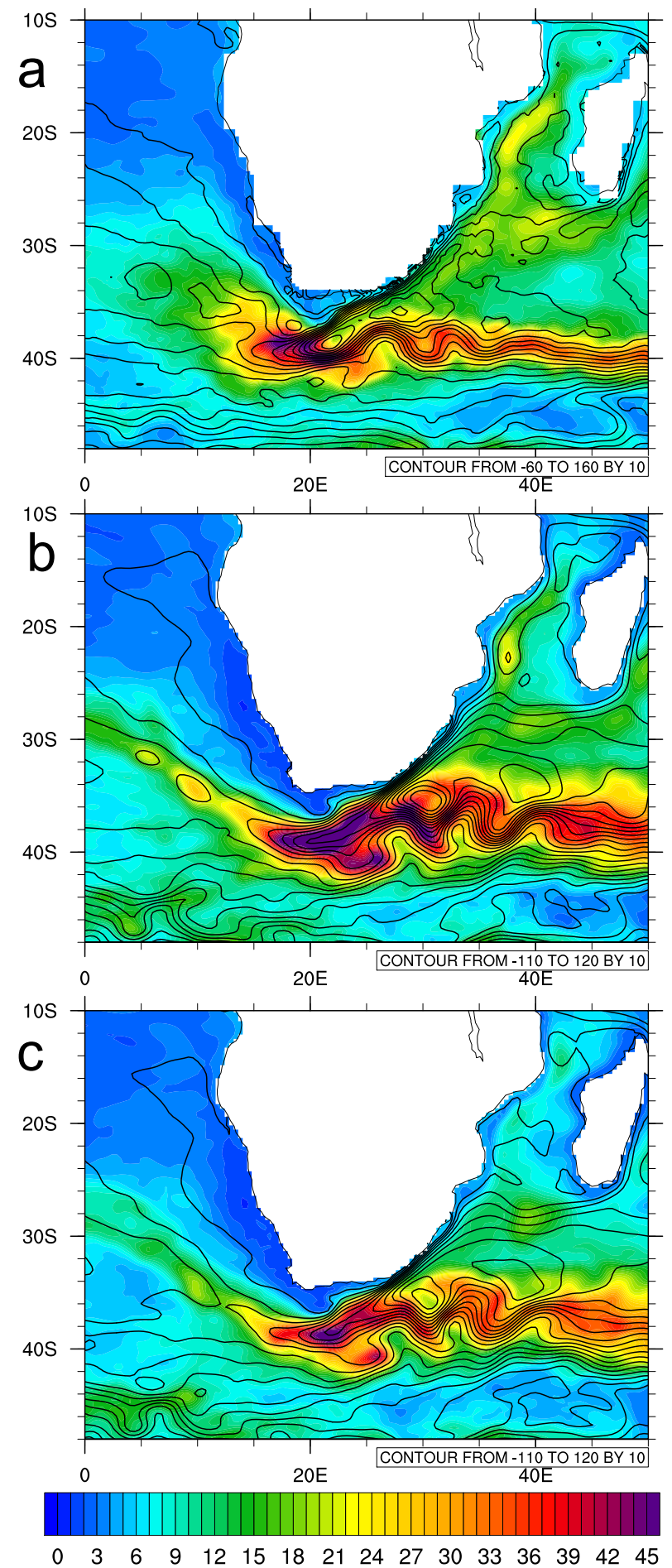

Fig. 3. Contour of mean dynamic topography and standard deviation (colors, in cm) from (a) satellite altimetry, (b) POP_CTRL and (c) POP_noITF near the tip of South Africa.

around $26^{\circ} \mathrm{E}$, just north of the Agulhas Plateau (Fig. 4b). After this point, the AC often breaks up into eddies instead of being a narrow jet following the coast like it is seen in the
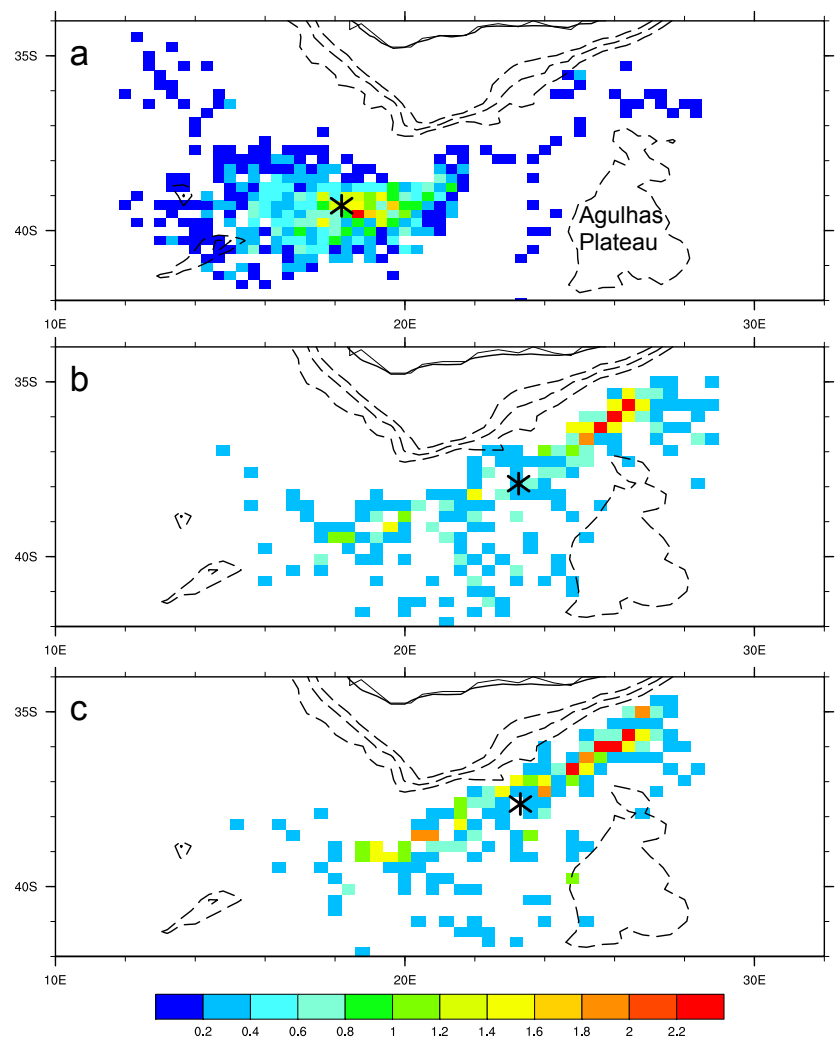

Fig. 4. Probability density of the retroflection position from (a) satellite altimetry, (b) POP_CTRL and (c) POP_NoITF simulation. The black crosses indicate the average retroflection position from the all time series. Bathymetric contours are at depth of $1000 \mathrm{~m}$, $2000 \mathrm{~m}$ and $3000 \mathrm{~m}$.

altimetry. This results in an average retroflection position at $23^{\circ} \mathrm{E}$ in the model, which is $5^{\circ}$ too far east. The same behavior of the $\mathrm{AC}$ was seen in a $0.1^{\circ}$ horizontal resolution regional configuration of the Hybrid Coordinate Ocean Model (HYCOM) and was greatly improved by replacing the 2 nd order momentum advection scheme by a 4th order scheme (Backeberg et al., 2009). The 2nd order momentum advection scheme of POP could then be responsible for the early retroflection of the $\mathrm{AC}$.

A too easterly retroflection position might be one of the causes for the regular path of the Agulhas eddies. In fact, most of the time in the model the eddies enter the Atlantic at the southern tip of the continental margin of South Africa at $37^{\circ} \mathrm{S}$, whereas the observations show that eddies can form as far south as $42^{\circ} \mathrm{S}$ and that the path they follow depends on the formation location (Dencausse et al., 2010a). Another possible cause for the very regular path of the eddies could be related to the seasonal cycle atmospheric forcing used in this simulation. Coupling POP with an atmospheric model showed an increased dispersion of the eddy paths (McClean et al., 2011). 

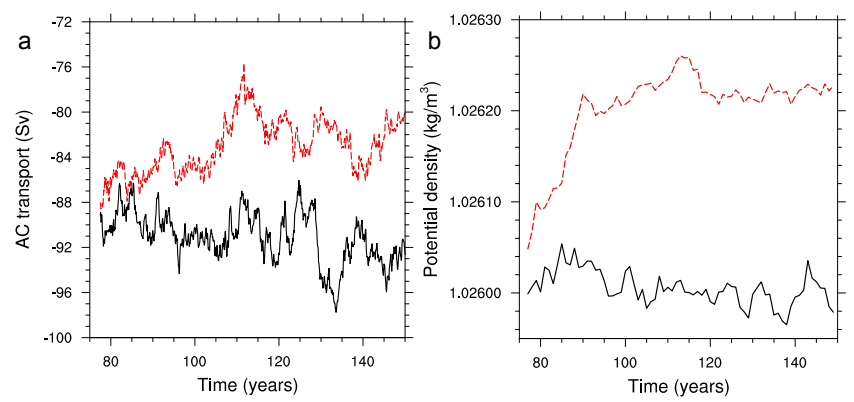

Fig. 5. Time series of the five-year running average (a) AC transport at $32^{\circ} \mathrm{S}$ and (b) average potential density of the upper $1000 \mathrm{~m}$ in the retroflection area $\left(40^{\circ} \mathrm{S}\right.$ to $37^{\circ} \mathrm{S}$ and $20^{\circ} \mathrm{E}$ to $\left.25^{\circ} \mathrm{E}\right)$. Black lines for POP_CTRL and red for POP_NoITF. We see the important interannual variability of the $\mathrm{AC}$ and the spin-up time of approximately $35 \mathrm{yr}$ of the surface density.

It is interesting to notice that the combination of a retroflection too far east and a regular path of the Agulhas eddies is common in state-of-the-art ocean models. It can be seen in global high-resolution models like OFES (Masumoto et al., 2004) and even in ECCO2 (Menemenlis et al., 2008 ) in which data assimilation is used. However, a regional configuration of ROMS (Penven et al., 2006) and a regional high-resolution nest based on NEMO-ORCA (Biastoch et al., 2008b) seem to perform better in this region. Analyzing the processes causing the differences between these model results would be useful for the ocean modeling community but is outside of the scope of this paper.

In summary, the results from POP compare more favorably with observed sea surface height field properties on aspects of Agulhas retroflection and Agulhas leakage than all models previously used in Indonesian Passage closure studies (as discussed in the introduction). Remaining discrepancies arise probably due to (still too) high values of mixing coefficients and the fact that the model is forced by mean seasonal fluxes.

\section{Effects of closure of the Indonesian passage}

As mentioned in Sect. 2, the POP_CTRL and POP_NoITF simulations were run from model year 75 to year 150 . The $\mathrm{AC}$ transport and the top $1000 \mathrm{~m}$ average potential density in the $\mathrm{AC}$ retroflection region show that after year 110 a statistical equilibrium of the surface flow seems to be reached (Fig. 5). We therefore choose to focus on the period year 110 to year 150. During this period the AC transport has an important inter-annual variability, the $5 \mathrm{yr}$ running mean shows a range between 88 and $97 \mathrm{~Sv}$ but the average density is more stable.

\subsection{Mean transports}

The spatial pattern of the difference of the $40 \mathrm{yr}$ average horizontal velocity fields (POP_CTRL minus POP_NoITF) is shown in Fig. 6. Changes in volume transports across important sections due to the closure of the Indonesian Passage are given in Table 2. As expected by Sverdrup theory (Hirst and Godfrey, 1993), opening the Indonesian Passage results in a decrease of the East Australian Current (EAC) transport between 20 and $35^{\circ} \mathrm{S}$. At $32^{\circ} \mathrm{S}$ the decrease is $13 \mathrm{~Sv}$ which is almost equal to the ITF transport. This leads to a weakening of both the Tasman Front transport and the EAC extension transport. The Tasman Leakage is hard to compute south of Tasmania because it is very close to the eastward Antarctic Circumpolar Current (ACC). For this reason we have chosen a meridional section at $120^{\circ} \mathrm{E}$ south of the Australian continent (indicated in Fig. 6) where the westward flow coming from the Tasman Leakage is far from the ACC and we can determine it more accurately. The input of water from the Pacific to the Indian Ocean through the Tasman Leakage decreases by about $2 \mathrm{~Sv}$, so we can conclude that an opening of the Indonesian Passage leads to increase of the net flow of water into the Indian Ocean of about $13 \mathrm{~Sv}$.

The opening of the Indonesian Passage also leads to an increase of the South Equatorial Current transport and strengthens both the Mozambique Channel flow $(+15 \mathrm{~Sv})$ and the South East Madagascar Current (SEMC) flow $(+3 \mathrm{~Sv})$. The Mozambique Channel transport would be reduced to almost nothing (2 Sv) if there was no ITF (Table 2). Assuming that the Tasman Leakage inflow does not reach as far north as the SEMC, we see that the $15 \mathrm{~Sv}$ increase of ITF leads to a $18 \mathrm{~Sv}$ total increase of the Mozambique Channel and SEMC. This could be due to an increase inertial recirculation in the SEMC (Fig. 2) or a small eastward migration of the South Indian Ocean Counter Current (Siedler et al., 2006; Palastanga et al., 2007).

The increased transport of the Mozambique Channel and the SEMC is only compensated by a small decrease of the Tasman Leakage transport leading to an increase of the AC transport of $10 \mathrm{~Sv}$. It is interesting to note that given the increase and decrease of the sources of the AC one would expect an increased AC transport of $16 \mathrm{~Sv}$. The reason why it is not seen here is likely to be related to an increase of the "Leeuwin Current system", defined by Hirst and Godfrey (1993) as the combination of southeastward geostrophic flow around $25^{\circ} \mathrm{S}$, southward flow at the west coast of Australia, coastal downwelling and a northwestward return flow at depth. The surface part of this system is seen to be strengthened by the ITF (see Fig. 2b,c) as found previously by Hirst and Godfrey (1993) and Valsala and Ikeda (2007).

\subsection{Agulhas Leakage}

The increase in AC transport due to the opening of the Indonesian Passage leads to both an increase of Agulhas leakage to the Atlantic $(+3 \mathrm{~Sv})$ and an increased transport of the Agulhas Return Current. In the South Atlantic the additional leakage mostly stays in the subtropical gyre, increasing the 


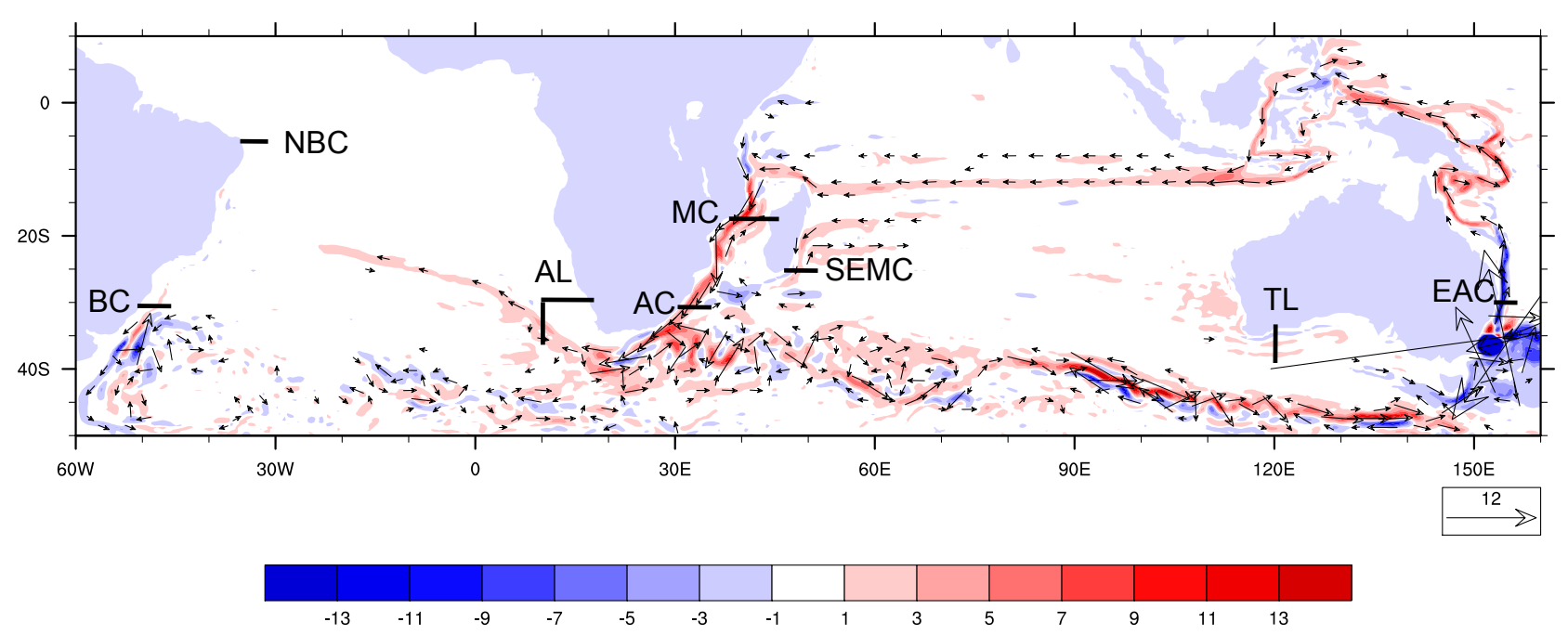

Fig. 6. Velocity difference (arrows, with the length of the arrow corresponding to $12 \mathrm{~cm} \mathrm{~s}^{-1}$ indicated) between POP_CTRL and POP_NoITF. The difference of the magnitude in $\mathrm{cm} \mathrm{s}^{-1}$ is shown in color. Velocities are vertically averaged from the surface to the depth of $1500 \mathrm{~m}$ and temporally over the last $40 \mathrm{yr}$ of the simulations. Sections used for Table 2 are also shown here (EAC: East Australian Current at $30^{\circ} \mathrm{S}$, TL: Tasman Leakage, NBC: North Brazil Current at $6^{\circ}$ S, SEMC: South East Madagascar Current, BC: Brazil Current at $32^{\circ}$ S, AL: Agulhas leakage, AC: Agulhas Current at $32^{\circ} \mathrm{S}, \mathrm{MC}$ : Mozambique Channel).

Brazil Current by $(+3 \mathrm{~Sv})$. A little part seems to escape further north to strengthen the North Brazil Current $(+1 \mathrm{~Sv})$.

The increased AL originates from an increase of the number of Agulhas eddies (see Table 2) which leads to increased variability of the SSH in the eddy corridor from 21 to $27 \mathrm{~cm}$ (Fig. 7). The variability of the longitudinal position of the retroflection also increases (not shown) but the average stays at the same position (Fig. 4b, c). This means that we find an important strengthening of the AC transport that has no effect on the mean retroflection position. This is not what would be expected from the non-linear theory developed by Ou and De Ruijter (1986) in which the separation location was shown to be very sensitive to the AC transport.

There are different hypotheses to explain the small sensitivity of the retroflection position. The control by bottom topography, in this case the Agulhas plateau, might be strong as suggested by Matano (1996) and could cause a "locking" of the retroflection in one position (De Ruijter et al., 1999). However even though in the models the retroflection is often located north of the Agulhas Plateau (Fig. 4) the mean position is $3^{\circ}$ further west due to repeated intrusion of the AC west of the Agulhas Plateau. Time series of the low frequency variability of the longitudinal position show an important variability (Fig. 8a) suggesting that the retroflection position is not locked by topographic features.

If we look at the relation between the low frequency variations of the AC and the longitudinal position of the retroflection, we see that in this model there is no simple linear relation (Fig. 8b). For most of the values of the AC transport the average retroflection is between 23 and $23.5^{\circ} \mathrm{E}$. The only remarkable event is a far east retroflection associated with a very weak $\mathrm{AC}$ and this could be due to the fact that a weaker current would be more sensitive to the effect of bottom topography. We see that even though we do not find a general relation between $\mathrm{AC}$ and retroflection position there are events (of five years duration) during which the $\mathrm{AC}$ transport is stronger combined with an eastward shift of the retroflection. Such a result was used by Van Sebille et al. (2009b) to illustrate the importance of the inertial overshoot mechanism (using another high resolution model) but in POP also the opposite response is found frequently.

\section{Analysis using HIM}

With the idealized model setup, we can control the retroflection regime by changing the amplitude of the wind stress (Le Bars et al., 2012). Hence, performing sensitivity studies with the wind stress strength for both an open (simulations referred to as HIM_CTRL) and closed Indonesian Passage (simulations indicated as HIM_NoITF ) can help interpret the POP results. In HIM_CTRL, the ITF varies from 1 to $16 \mathrm{~Sv}$ over the wind stress range used $\left(0.05-0.3 \mathrm{~N} \mathrm{~m}^{-2}\right)$.

An important indicator of the Agulhas retroflection is the retroflection index $R$ (Dijkstra and de Ruijter, 2001a; Le Bars et al., 2012), defined by

$R=1-\frac{\Phi_{\mathrm{L}}}{\Phi_{\mathrm{AC}}}$,

where $\Phi_{\mathrm{L}}$ and $\Phi_{\mathrm{AC}}$ are the Agulhas leakage and the AC transport, respectively. Hence, $R$ is a non-dimensional number that represents the proportion of AC transport that is retroflected. With reference to the results in the previous 

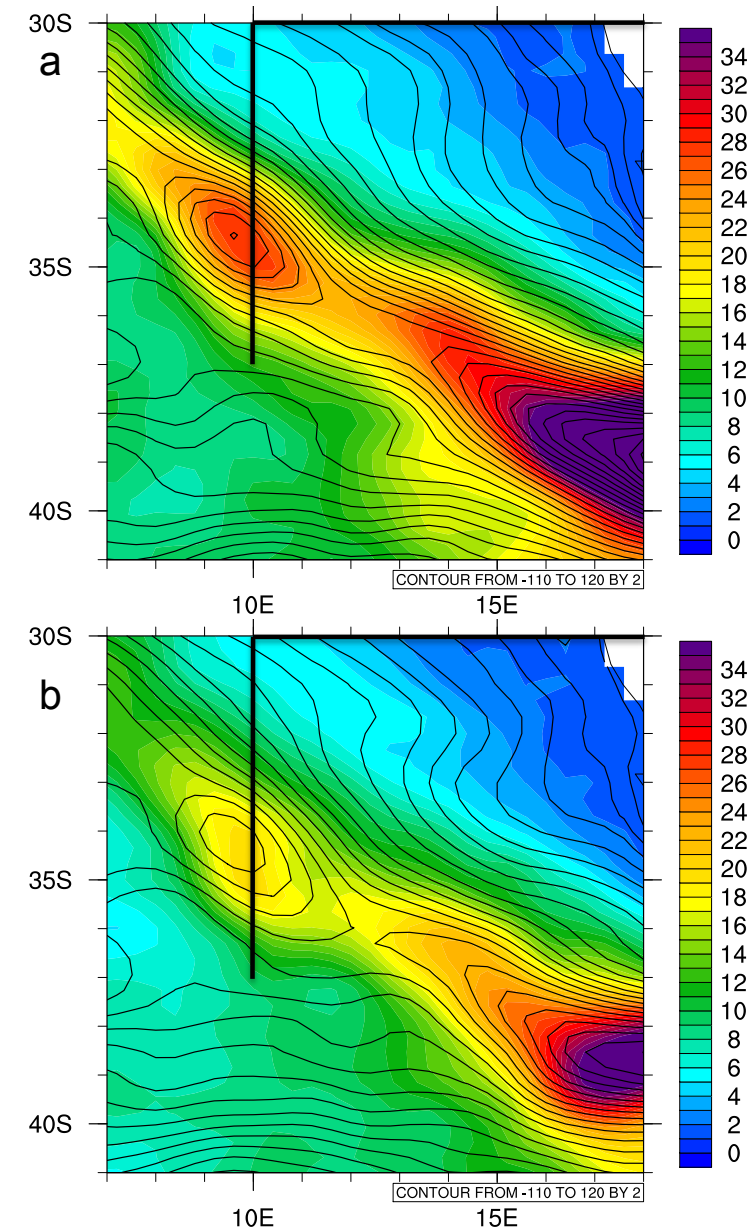

Fig. 7. Contour of mean dynamic topography and standard deviation (colors, in cm) from (a) POP_CTRL and (b) POP_ITF. This zoom on the Agulhas eddy corridor shows the increase variability due to an opening of the Indonesian Passage. The black line shows the section used to compute the Agulhas leakage.

section, $R$ is very similar for POP_CTRL $(R=0.78)$ and POP_NoITF $(R=0.79)$. This result is surprising, as it means that opening the ITF does not affect the proportion of water that is retroflected.

To assess the generality of this result we compare $R$ values computed for HIM_CTRL and HIM_NoITF for different wind stress amplitudes. As can be seen Fig. 9a, the retroflection index $R$ is insensitive to the presence of the ITF for all wind stress amplitudes. As the AC transport increases with the ITF, an opening of the Indonesian Passage will always strengthen the leakage (Fig. 9b). The fact that $R$ is insensitive to the ITF strength is intriguing as for an increase in AC transport due to a stronger wind, $R$ increases (Le Bars et al., 2012). This suggests that the partitioning of the transports in the leakage and return current is dominated by the wind field.

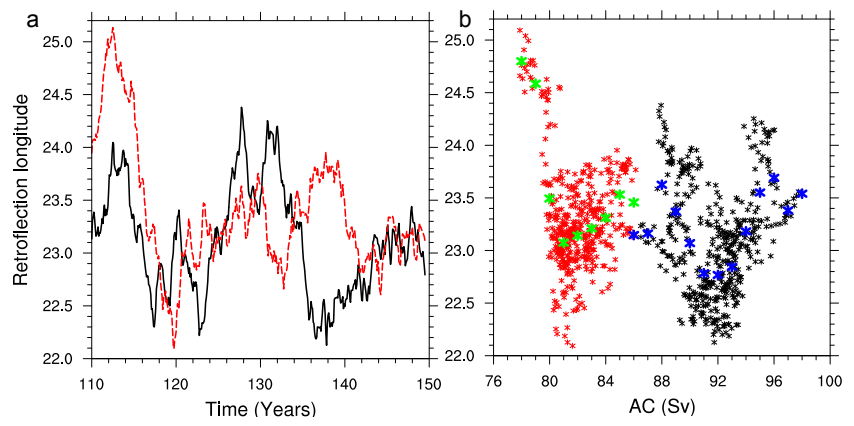

Fig. 8. (a) Five-year running mean of the longitude of the retroflection in POP_CTRL (black) and POP_NoITF (red). (b) Longitude of the retroflection as a function of AC transport for POP_CTRL (black) and POP_NoITF (red) also filtered with a five-year running mean. Bigger crosses represent the average AL corresponding to a certain range of $1 \mathrm{~Sv}$ of $\mathrm{AC}$.

From the HIM results one can deduce an empirical relation between the difference in the Agulhas leakage between the open $\left(\Phi_{\mathrm{L}}^{\mathrm{O}}\right)$ and closed $\left(\Phi_{\mathrm{L}}^{\mathrm{C}}\right)$ cases. By definition the leakage in these two cases is given by

$\Phi_{\mathrm{L}}^{\mathrm{O}}=\Phi_{\mathrm{AC}}^{\mathrm{O}} \cdot\left(1-R^{\mathrm{O}}\right) ; \Phi_{\mathrm{L}}^{\mathrm{C}}=\Phi_{\mathrm{AC}}^{\mathrm{C}} \cdot\left(1-R^{\mathrm{C}}\right)$,

where the superscripts $O$ and $C$ refer to the HIM_CTRL and HIM_NoITF results, respectively. From Fig. 9a, we deduce that for all wind stress amplitudes $\tau$, we have approximately $R^{\mathrm{O}}(\tau) \approx R^{\mathrm{C}}(\tau) \equiv R(\tau)$ which reflects the independence of $R$ on the ITF amplitude. In addition, in this model the difference between the AC transport in the HIM_CTRL and HIM NoITF is equal to the ITF in the model, i.e. $\Phi_{\mathrm{AC}}^{\mathrm{C}}(\tau) \approx$ $\Phi_{\mathrm{AC}}^{\mathrm{O}}(\tau)-\Phi_{\mathrm{ITF}}^{\mathrm{O}}(\tau)$.

It follows directly from (3) that the leakage difference is given by

$\Phi_{\mathrm{L}}^{\mathrm{O}}(\tau)-\Phi_{\mathrm{L}}^{\mathrm{C}}(\tau) \approx \Phi_{\mathrm{ITF}}(\tau) \cdot(1-R(\tau))$.

A comparison of the time mean of the left hand side and right hand side of (Eq. 4) is shown in Fig. 10. Although the leakage has a large variability, there is a reasonable balance of both time mean terms. The balance (Eq. 3) does not strictly hold for POP, but for a wind stress amplitude between 0.25 and $0.3 \mathrm{~N} \mathrm{~m}^{-2}$, corresponding to an ITF transport of 14 to $16 \mathrm{~Sv}$ in HIM_CTRL, the result (Eq. 4) provides an increased leakage of around $4.5 \mathrm{~Sv}$, which is at least consistent with what was found in POP.

The fact that POP and HIM give similar results concerning the retroflection index even with different continent geometry, bottom topography, vertical coordinates and surface forcing highlights the generality of our results.

\section{Summary and discussion}

In this work we have extended the results of previous modeling studies on the role of the ITF in the global climate system, 

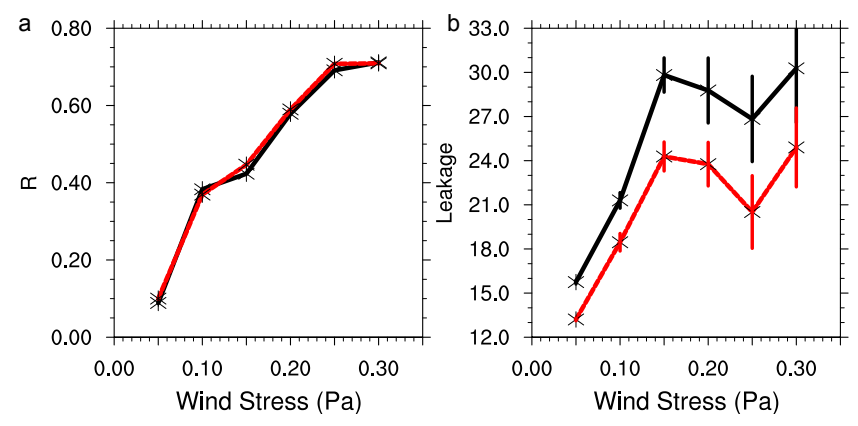

Fig. 9. Retroflection index (a) and Agulhas leakage (b) as a function of wind stress for HIM_CTRL (black) and HIM_NoITF (red). Each cross represent a statistical steady state and vertical bars represent the $95 \%$ confidence interval for the computation of the mean Agulhas leakage.

by focussing on the impact of the ITF on the volume of Agulhas leakage (AL) in a strongly eddying ocean model (POP at $0.1^{\circ}$ horizontal resolution). In this version of POP, boundary layer flows as well as meso-scale eddies are better resolved that in the previous modeling efforts related to the climate effects of the ITF (Schneider, 1998; Lee et al., 2002; Wajsowicz and Schneider, 2001; Song et al., 2007).

In POP the AL increases due to the opening of the Indonesian Passage. This response was shown to be due to the combined effect of an increase $\mathrm{AC}$ transport due to the additional input of water from the Pacific and a constant proportion of Agulhas Current retroflection (constant retroflection index). The increase of $\mathrm{AL}$ is associated with an increased number of Agulhas eddies. The issue of the effect of ITF on the heat and salt transport from the Indian to the South Atlantic and its impact on the Atlantic Meridional Overturning is outside the scope of this paper because it involves a complex competition between changes of the so-called "warm route" through the AL and the "cold route" through the Pacific and the Drake Passage (Gordon, 1986).

A two-layer model was used to investigate the change of the retroflection index with opening/closing the Indonesian Passage. We show that for a wide range of wind stress forcing the retroflection index is insensitive to the strength of the ITF. For this model we are also able to deduce a semi-empirical formula that relates the ITF transport and the leakage.

The fact that the retroflection index stays constant is intriguing. As mentioned in the previous section, one would expect an increase retroflection index due to mixed barotropic/baroclinic instabilities related to an increase $\mathrm{Ag}$ ulhas Current forced by Indian Ocean winds (Le Bars et al., 2012). The experiment realized here is however different because the input of water comes from the Pacific Ocean and needs to return south of Australia. To isolate this additional large-scale condition we solve the linear momentum and mass conservation equations on the same domain. The

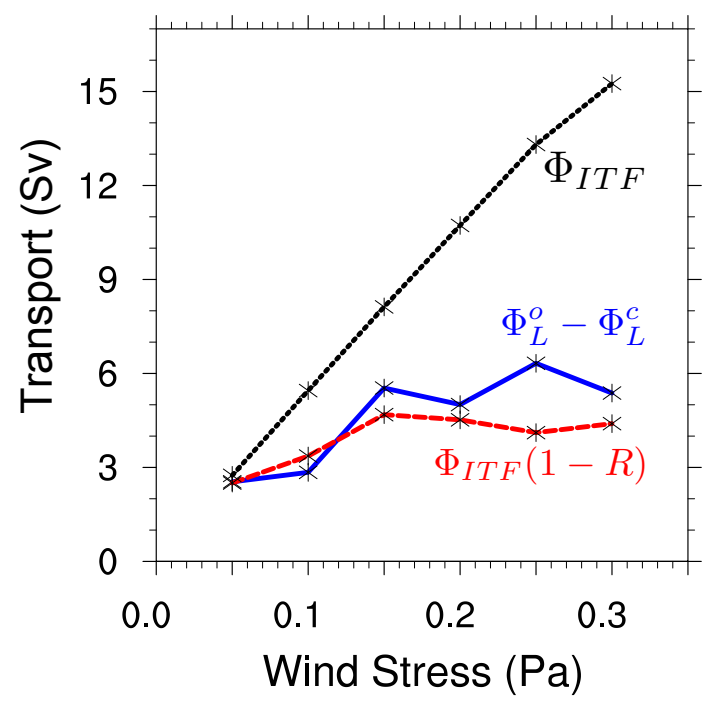

Fig. 10. Comparison of the right hand side and the left hand side of Eq. (4) for the equilibrium solutions of HIM_CTRL and HIM_NoITF.

derivation is presented in Appendix A and we discuss here the main results.

In a linear model the retroflection index is independent of the wind stress. This can be understood because it lacks all the mechanisms put forward by Dijkstra and de Ruijter (2001a) and Le Bars et al. (2012) to explain the change of the retroflection index, i.e. viscosity, inertia or turbulence, depending on the dynamical regime. In this model, the retroflection index decreases when the Indonesian Passage is opened which is consistent with the potential vorticity constraints on the flow and the fact that the water has to return at a latitude south of Australia.

The fact that the retroflection index does not change when the Indonesian Passage opens is then the result of two mechanisms: (i) increase barotropic/baroclinic instabilities that are expected to increase the retroflection and (ii) large-scale linear momentum and mass balances that lead to decrease the retroflection. Understanding why these two effects nearly cancel each other for each amplitude of the wind forcing is a challenge left for future research.

\section{Appendix A}

\section{Linear model}

To further understand the physics of the previous results we use a steady linear one-layer quasi-geostrophic model. We want to investigate whether the fact that the retroflection index stays constant when the ITF is open is the result of steady linear mass and vorticity balances. Using the same geometry as used for the HIM model, we define seven sections (see Fig. A1) and assuming a steady state we have the following 


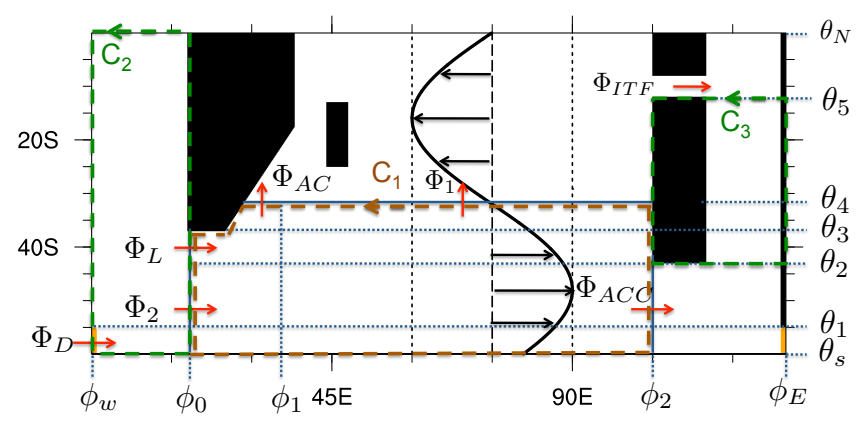

Fig. A1. Domain of computation with the main sections along which the transport is computed and the contours of integration $C_{1}$, $C_{2}$ and $C_{3}$.

mass balances:

$$
\begin{aligned}
\Phi_{L}+\Phi_{2} & =\Phi_{\mathrm{ITF}}+\Phi_{A C C}, \\
\Phi_{\mathrm{AC}}+\Phi_{1} & =\Phi_{\mathrm{ITF}}, \\
\Phi_{D} & =\Phi_{L}+\Phi_{2} .
\end{aligned}
$$

We now write the steady quasi-geostrophic equations in the form $\mathbf{F}=0$, with

$$
\begin{aligned}
& F_{1}=\mathbf{u} . \nabla u-f v+\frac{1}{\rho} \frac{\partial p}{\partial x}-\frac{\tau^{\phi}}{\rho H}-A_{H} \nabla^{2} u, \\
& F_{2}=\mathbf{u} . \nabla v+f u+\frac{1}{\rho} \frac{\partial p}{\partial y}-A_{H} \nabla^{2} v,
\end{aligned}
$$

where $H$ is the thickness of the layer having a constant density $\rho$. Furthermore, $f$ is the Coriolis parameter and $A_{H}$ the lateral friction coefficient. We now integrate $\mathbf{F}$ over three closed contours $C_{1}, C_{2}$ and $C_{3}$ as indicated in the Fig. A1; i.e. $\oint \mathbf{F} . \mathbf{d s}=0$. Inertia is neglected, friction is only considered in the Agulhas Current and the contour integrated pressure gradient cancels for closed contours. On $C_{1}$ this gives

$$
\begin{aligned}
& \int_{\phi_{0}}^{\phi_{2}}-\frac{\tau^{\phi}\left(\theta_{S}\right)}{\rho H} r_{0} \cos \theta_{S} d \phi+\int_{\theta_{s}}^{\theta_{2}} f u\left(\phi_{2}, \theta\right) r_{0} d \theta+ \\
& \int_{\phi_{1}}^{\phi_{2}} f v\left(\phi, \theta_{4}\right) r_{0} \cos \theta_{4} d \phi+\int_{\phi_{0}}^{\phi_{1}} f v\left(\phi, \theta_{4}\right) r_{0} \cos \theta_{4} d \phi+ \\
& \int_{\phi_{0}}^{\phi_{2}} \frac{\tau^{\phi}\left(\theta_{4}\right)}{\rho H} r_{0} \cos \theta_{4} d \phi+\int_{\theta_{3}}^{\theta_{4}} A_{H} \nabla^{2} v\left(\phi_{0}, \theta\right) r_{0} d \theta+ \\
& \int_{\theta_{2}}^{\theta_{2}}-f u\left(\phi_{0}, \theta\right) r_{0} d \theta+\int_{\theta_{s}}^{\theta_{2}}-f u\left(\phi_{0}, \theta\right) r_{0} d \theta=0,
\end{aligned}
$$

where $r_{0}$ is the radius of the earth. We now integrate the equation vertically between $-H$ and 0 and we use a midpoint ap- proximation for $f$ on each interval to give

$$
\begin{aligned}
& -\frac{\left(\phi_{2}-\phi_{0}\right)}{\rho} r_{0} \cos \theta_{s} \tau^{\phi}\left(\theta_{s}\right)+f_{2 s} \Phi_{A C C}+ \\
& f\left(\theta_{4}\right)\left(\Phi_{1}+\Phi_{\mathrm{AC}}\right)+\frac{\left(\phi_{2}-\phi_{0}\right)}{\rho} r_{0} \cos \theta_{s} \tau^{\phi}\left(\theta_{4}\right)+ \\
& H \int_{\theta_{3}}^{\theta_{4}} A_{H} \nabla^{2} v\left(\phi_{0}, \theta\right) r_{0} d \theta-f_{23} \Phi_{\mathrm{AC}} \\
& -f_{2 s} \Phi_{2}+\frac{\left(\phi_{2}-\phi_{0}\right)}{\rho} r_{0} \cos \theta_{4} \tau^{\phi}\left(\theta_{4}\right)=0,
\end{aligned}
$$

where

$$
f_{i j}=f\left(\frac{\theta_{i}+\theta_{j}}{2}\right) \text {. }
$$

Using the vorticity balance at the WBC then, under no-slip boundary conditions, it is possible to express the horizontal friction as a function of the wind stress (Eq. 2.11.6 from Pedlosky, 1996):

$$
\begin{aligned}
\int_{\theta_{3}}^{\theta_{4}} A_{H} & \nabla^{2} v\left(\phi_{0}, \theta\right) r_{0} d \theta=-\int_{\theta_{3}}^{\theta_{4}} \int_{\phi_{0}}^{\phi_{2}} \frac{f}{H} \operatorname{curl}\left(\frac{\boldsymbol{\tau}}{\rho f}\right) r_{0}^{2} \cos \theta d \phi d \theta \\
& =\int_{\theta_{3}}^{\theta_{4}} \int_{\phi_{0}}^{\phi_{2}} \frac{f}{H \rho r_{0} \cos \theta} \frac{d}{d \theta}\left(\frac{\tau^{\phi} \cos \theta}{f}\right) r_{0}^{2} \cos \theta d \phi d \theta \\
& =-\frac{\left(\phi_{2}-\phi_{0}\right) r_{0} \tau_{0}}{H \rho} K
\end{aligned}
$$

with

$$
K=\int_{\theta_{3}}^{\theta_{4}} \alpha \cos \alpha\left(\theta-\theta_{0}\right) \cos \theta-\sin \alpha\left(\theta-\theta_{0}\right) d \theta .
$$

We now group all the terms of Eq. (A3) that only depend on the wind stress to give

$$
f_{2 s} \Phi_{A C C}+f_{4}\left(\Phi_{1}+\Phi_{\mathrm{AC}}\right)-f_{23} \Phi_{L}-f_{2 s} \Phi_{2}=G\left(\tau^{\phi}\right)
$$

with

$$
G\left(\tau^{\phi}\right)=\frac{\left(\phi_{2}-\phi_{0}\right)}{\rho} r_{0}\left(\cos \theta_{s} \tau^{\phi}\left(\theta_{s}\right)+\tau_{0} K\right) .
$$

The integration of $\mathbf{F}$ over contour $C_{2}$ gives

$$
\begin{aligned}
& \int_{\phi_{W}}^{\phi_{0}}-\frac{\tau^{\phi}\left(\theta_{s}\right)}{\rho H} r_{0} \cos \theta_{s} d \phi+\int_{\theta_{s}}^{\theta_{2}} f u\left(\Phi_{0}, \theta\right) r_{0} d \theta+ \\
& \int_{\theta_{2}}^{\theta_{3}} f u\left(\Phi_{0}, \theta\right) r_{0} d \theta+\int_{\phi_{W}}^{\phi_{0}} \frac{\tau^{\phi}\left(\theta_{N}\right)}{\rho H} r_{0} \cos \theta_{N} d \phi+ \\
& \int_{\theta_{s}}^{\theta_{1}}-f u\left(\Phi_{W}, \theta\right) r_{0} d \theta=0 .
\end{aligned}
$$



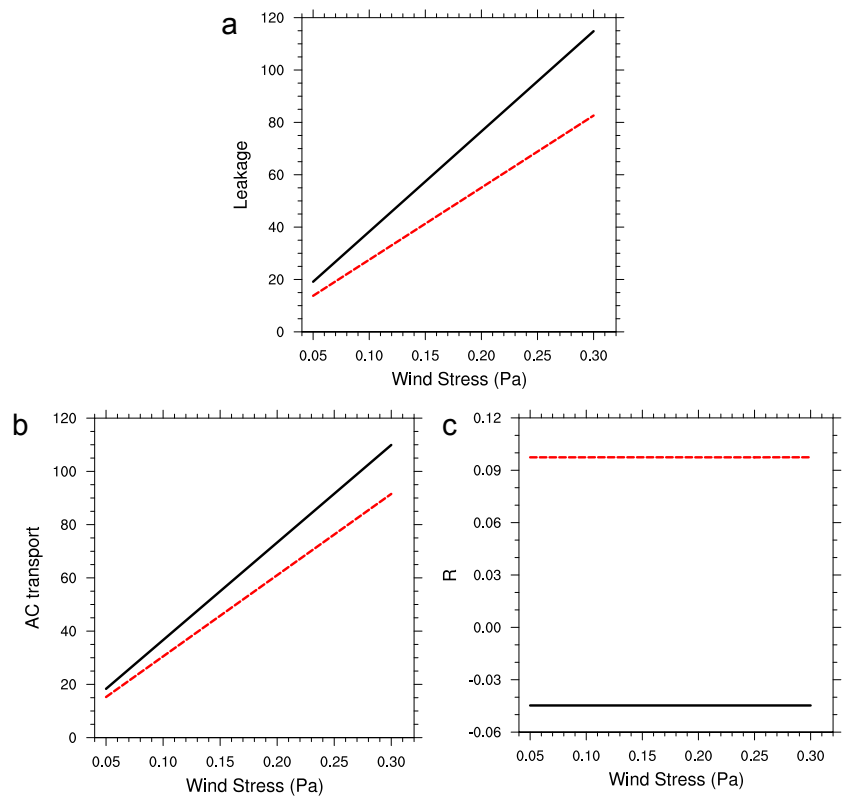

Fig. A2. Agulhas leakage (a), Agulhas Current transport (b) and retroflection index (c) as a function of wind stress computed from the linear model in cases where the Indonesian Passage is open (black) and closed (red).

Finally for a contour east of Australia this method leads to the linear island rule (LIR) (Godfrey, 1989):

$\Phi_{\mathrm{ITF}}=\frac{r_{0}\left(\phi_{E}-\phi_{2}\right)\left(\tau^{\phi}\left(\theta_{5}\right) \cos \theta_{5}-\tau^{\phi}\left(\theta_{2}\right) \cos \theta_{2}\right)}{\rho\left(f\left(\theta_{5}\right)-f\left(\theta_{2}\right)\right)}$.

We now have seven unknowns and six equations, to close the problem we approximate $\Phi_{1}$ with the Sverdrup balance:

$$
\begin{aligned}
\Phi_{1} & =\frac{f}{\beta} \int_{\phi_{1}}^{\phi_{2}} \operatorname{curl}\left(\frac{\boldsymbol{\tau}}{\rho f}\right) \cos \theta_{4} d \phi \\
& =\frac{\left(\phi_{2}-\phi_{1}\right) \tau_{0}}{\rho \beta}\left(\alpha \cos \alpha\left(\theta_{4}-\theta_{0}\right) \cos \theta_{4}-\sin \alpha\left(\theta_{4}-\theta_{0}\right)\right) .
\end{aligned}
$$

From this set of equations we can compute the AC transport:

$\Phi_{\mathrm{AC}}=\Phi_{\mathrm{ITF}}-\Phi_{1}$,

and the leakage:

$\Phi_{L}=\frac{1}{f_{2 s}-f_{23}}\left(\left(f_{2 s}-f_{4}\right) \Phi_{\mathrm{ITF}}+G\left(\tau^{\phi}\right)\right)$.

The transports $\Phi_{\mathrm{AC}}$ and $\Phi_{\mathrm{L}}$ are plotted as a function of $\tau_{0}$ in Fig. A2. We see that as both $\Phi_{\mathrm{L}}$ (Fig. A2a) and $\Phi_{\mathrm{AC}}$ (Fig. A2b) are linearly increasing with the wind stress magnitude and the retroflection index does not depend on the forcing. This result is expected because the mechanisms responsible for an increase of the retroflection index are related to inertia and turbulence as analyzed by Dijkstra and de Ruijter (2001a) and Le Bars et al. (2012). However, opening the Indonesian Passage leads to an important decrease of the retroflection index $R$ (Fig. A2c) that even becomes negative. This is because the transport $\Phi_{L}$ is affected more strongly by the ITF than the transport $\Phi_{A L}$. The value of the parameter $\left(f_{2 s}-f_{4}\right) /\left(f_{2 s}-f_{23}\right)$ is approximately 1.8 , meaning that each increase of $\Phi_{\text {ITF }}$ of $1 \mathrm{~Sv}$ leads to increase $\Phi_{L}$ by $1.8 \mathrm{~Sv}$. If we take equation (A8) and remove the case where $\Phi_{\text {ITF }}$ is null then we obtain

$f_{2 s} \Phi_{A C C_{\mathrm{ITF}}}+f_{4} \Phi_{\mathrm{ITF}}-f_{23} \Phi_{L_{\mathrm{ITF}}}-f_{2 s} \Phi_{2 \mathrm{ITF}}=0$,

where $\Phi_{A C C_{\mathrm{ITF}}}, \Phi_{L_{\mathrm{ITF}}}$ and $\Phi_{2_{\mathrm{ITF}}}$ are the transports directly forced by $\Phi_{\text {ITF }}$ and independent of the Indian Ocean wind. We combine this equation with the following mass balance:

$\Phi_{A C C_{\mathrm{ITF}}}+\Phi_{\mathrm{ITF}}=\Phi_{L_{\mathrm{ITF}}}+\Phi_{2_{\mathrm{ITF}}}$

to obtain:

$\Phi_{L_{\mathrm{ITF}}}=\frac{f_{2 s}-f_{4}}{f_{2 s}-f_{23}} \Phi_{\mathrm{ITF}}$.

We see that a simple explanation for the important increase of $\Phi_{L}$ is that the Coriolis parameter difference between the latitude where the Indonesian Throughflow enters and where the ACC leaves the Indian Ocean is more important than the difference between where the leakage leaves and the ACC enters. Another phenomenon that is not allowed by this model but that could happen in the real ocean would be that south of Africa the ACC position moves further south, increasing the momentum difference with the leakage. However, we expect the position of the ACC fronts to be mostly set by wind stress and topography (Graham et al., 2013).

The values of the retroflection index in this model are unrealistic, $\sim 0.1$ for the closed ITF and $\sim-0.04$ for the open case. This is again because the processes that are responsible for the retroflection are not included in this model, in fact the small retroflection seen in the closed ITF case is purely due to sverdrup dynamics. The wind stress curl is stronger at the position where the AC transport is computed than at the latitude of the leakage. Such a small retroflection index can also be found in the HIM model when the inertia is weak (see Fig. $9 \mathrm{~b}$ for a wind stress of $0.05 \mathrm{~Pa}$ ). In baroclinic and barotropic shallow-water models such low values were shown to appear at the limit between a viscous and an inertial regime of retroflection (Dijkstra and de Ruijter, 2001a; Le Bars et al., 2012). The negative retroflection index seen in the open ITF case indicates a leakage larger than the AC. This can also be observed in numerical model when a local recirculation cell appears south of the African continent as discussed by Dijkstra and de Ruijter (2001a).

The linear model provides a simple mechanism based on mass and momentum balance that leads to a decrease of the retroflection index due the opening of the Indonesian Throughflow. However, alone it is not able to explain the 
HIM and POP result that the retroflection index is not affected by an opening of the Indonesian Passage.

Acknowledgements. The authors are funded by the Netherlands Organization for Scientific Research through the INATEX program, ZKO No. 839.08.430. Michael Kliphuis (IMAU-UU) is thanked for his assistance in carrying out the numerical computations with the POP model. We thank the DEISA Consortium (www.deisa.eu), co-funded through the EU FP6 project RI-031513 and the FP7 project RI-222919, for support of these computations (within the ITAMOC project lead by H. A. Dijkstra) within the DEISA Extreme Computing Initiative. Two anonymous referees are also thanked for their constructive comments on the manuscript.

Edited by: J. Schröter

\section{References}

Backeberg, B. C., Bertino, L., and Johannessen, J. A.: Evaluating two numerical advection schemes in HYCOM for eddyresolving modelling of the Agulhas Current, Ocean Sci., 5, 173190, doi:10.5194/os-5-173-2009, 2009.

Beal, L. M., De Ruijter, W. P. M., Biastoch, A., and Zahn, R.: On the role of the Agulhas system in ocean circulation and climate, Nature, 472, 429-436, 2011.

Biastoch, a., Böning, C. W., and Lutjeharms, J. R. E.: Agulhas leakage dynamics affects decadal variability in Atlantic overturning circulation., Nature, 456, 489-92, doi:10.1038/nature07426, 2008a.

Biastoch, a., Lutjeharms, J. R. E., Böning, C. W., and Scheinert, M.: Mesoscale perturbations control inter-ocean exchange south of Africa, Geophys. Res. Lett., 35, 2000-2005, doi:10.1029/2008GL035132, 2008b.

Bryden, H. L., Beal, L. M., and Duncan, L. M.: Structure and transport of the Agulhas Current and its temporal variability, J. Oceanogr., 61, 479-492, 2005.

De Ruijter, W. P. M., Biastoch, A., Drijfhout, S. S., Lutjeharms, J. R. E., Matano, R. P., Pichevin, T., Van Leeuwen, P. J., and Weijer, W.: Indian-Atlantic interocean exchange: Dynamics, estimation and impact, J. Geophys. Res., 104, 20,885-20,910, 1999.

Dencausse, G., Arhan, M., and Speich, S.: Routes of Agulhas rings in the southeastern Cape Basin, Deep Sea Res. I, 57, 1406-1421, doi:10.1016/j.dsr.2010.07.008, 2010a.

Dencausse, G., Arhan, M., and Speich, S.: Spatio-temporal characteristics of the Agulhas Current retroflection, Deep Sea Res. I, 57, 1392-1405, doi:10.1016/j.dsr.2010.07.004, 2010b.

Dijkstra, H. A. and de Ruijter, W. P. M.: On the physics of the Agulhas Current: Steady retroflection regimes, J. Phys. Oceanogr., 31, 2971-2985, doi:10.1175/15200485(2001)031<2971:OTPOTA > 2.0.CO;2, 2001a.

Dijkstra, H. A. and De Ruijter, W. P. M.: Barotropic instabilities of the Agulhas Current system and their relation to ring formation, J. Mar. Res, 59, 517-533, doi:10.1357/002224001762842172, $2001 b$.

Dukowicz, J. K. and Smith, R. D.: Implicit free-surface method for the Bryan-Cox-Semtner ocean model, J. Geophys. Res., 99, 7991-8014, doi:10.1029/93JC03455, 1994.
Godfrey, J. S.: A Sverdrup model of the depth-integrated flow for the world ocean allowing for island circulations, Geophys. Astrophys. Fluid Dynamics, 45, 89-112, 1989.

Gordon, A. L.: Interocean exchange of thermocline water, J. Geophys. Res., 91, 5037-5046, 1986.

Graham, R. M., de Boer, A. M., Heywood, K. J., Chapman, M., and Stevens, D. P.: Southern Ocean fronts: Controlled by wind or topography?, J. Geophys. Res., 117, C08018, doi:10.1029/2012JC007887, 2013.

Hallberg, R.: Stable split time stepping schemes for large-scale ocean modeling, J. Computational Physics, 135, 54-65, 1997.

Hirst, A. C. and Godfrey, J. S.: The role of the Indonesian Throughflow in a global ocean GCM, J. Phys. Oceanogr., 23, 1057-1086, doi:10.1175/1520-0485(1993)023<1057:TROITI > 2.0.CO;2, 1993.

Hurrell, J. W., Hack, J. J., Shea, D., Caron, J. M., and Rosinski, J.: A new sea surface temperature and sea ice boundary dataset for the Community Atmosphere Model, J. Climate, 21, 5145-5153, doi:10.1175/2008JCLI2292.1, 2008.

Large, W. G. and Yeager, S. G.: Diurnal to decadal global forcing for ocean and sea-ice models: the data sets and flux climatologies, Tech. rep., pp. National Center for Atmospheric Research, Boulder, 2004.

Le Bars, D., De Ruijter, W. P. M., and Dijkstra, H. a.: A new regime of the Agulhas Current retroflection: turbulent choking of Indian-Atlantic leakage., J. Phys. Oceanogr., 42, 1158-1172, doi:10.1175/JPO-D-11-0119.1, 2012.

Lee, T., Fukumori, I., Menemenlis, D., Xing, Z., and Fu, L.-L.: Effects of the Indonesian Throughflow on the Pacific and Indian Oceans, J. Phys. Oceanogr., 32, 1404-1429, doi:10.1175/15200485(2002)032<1404:EOTITO > 2.0.CO;2, 2002.

Maltrud, M. E. and McClean, J. L.: An eddy resolving global 1/10 ocean simulation, Ocean Modell., 8, 31-54, doi:10.1016/j.ocemod.2003.12.001, 2005.

Maltrud, M., Bryan, F., and Peacock, S.: Boundary impulse response functions in a century-long eddying global ocean simulation, Environ. Fluid Mech., 10, 275-295, 2010.

Masumoto, Y., Sasaki, H., Kagimoto, T., Komori, N., Ishida, A., Sasai, Y., Miyama, T., Motoi, T., Mitsudera, H., Takahashi, K., Sakuma, H., and Yamagata, T.: A fifty-year eddy-resolving simulation of the world ocean - preliminary outcomes of OFES (OGCM for the Earth Simulator) -, J. Earth Sim., 1, 35-56, 2004.

Matano, R. P.: A numerical study of the Agulhas Retroflection: The role of bottom topography, J. Phys. Oceanogr., 26, 2267-2279, 1996.

McClean, J. L., Bader, D. C., Bryan, F. O., Maltrud, M. E., Dennis, J. M., Mirin, A. a., Jones, P. W., Kim, Y. Y., Ivanova, D. P., Vertenstein, M., Boyle, J. S., Jacob, R. L., Norton, N., Craig, A., and Worley, P. H.: A prototype two-decade fully-coupled fine-resolution CCSM simulation, Ocean Modell., 39, 10-30, doi:10.1016/j.ocemod.2011.02.011, 2011.

Menemenlis, B. D., Campin, J.-m., Heimbach, P., Hill, C., and Lee, T.: ECCO2: High resolution global ocean and sea ice data synthesis, Mercator Ocean Quarterly Newsletter, 31, 13-21, 2008.

Ou, H. W. and De Ruijter, W. P. M.: Separation of an inertial boundary current from a curved coastline, J. Phys. Oceanogr., 16, 280289, 1986.

Palastanga, V., Leeuwen, P. J. V., Schouten, M. W., and Ruijter, W. P. M. D.: Flow structure and variability in the subtropical Indian 
Ocean : Instability of the South Indian Ocean Countercurrent, J. Geophys. Res, 112, 1-11, doi:10.1029/2005JC003395, 2007.

Pedlosky, J.: Ocean Circulation Theory, Springer, Verlag Berlin Heidelberg New York, 1996.

Penven, P., Lutjeharms, J. R. E., and Florenchie, P.: Madagascar : A pacemaker for the Agulhas Current system ?, Geophys. Res. Lett., 33, 0-4, doi:10.1029/2006GL026854, 2006.

Richardson, P. L.: Agulhas leakage into the Atlantic estimated with subsurface floats and surface drifters, Deep Sea Res. I, 54, 13611389, 2007.

Ridderinkhof, H., van der Werf, P. M., Ullgren, J. E., van Aken, H. M., van Leeuwen, P. J., and de Ruijter, W. P. M.: Seasonal and interannual variability in the Mozambique Channel from moored current observations, J. Geophys. Res., 115, C06010, doi:10.1029/2009JC005619, 2010.

Rouault, M., Penven, P., and Pohl, B.: Warming in the Agulhas Current system since the 1980's, Geophys. Res. Lett, 36, L12602, doi:10.1029/2009GL037987, 2009.

Schneider, N.: The Indonesian Throughflow and the global climate system, J. Climate, 11, 676-689, doi:10.1175/15200442(1998)011<0676:TITATG > 2.0.CO;2, 1998.

Siedler, G., Rouault, M., and Lutjeharms, J. R. E.: Structure and origin of the subtropical South Indian Ocean Countercurrent, Geophys. Res. Lett., 33, L24609, doi:10.1029/2006GL027399, 2006.

Song, Q., Vecchi, G. a., and Rosati, A. J.: The role of the Indonesian Throughflow in the Indo-Pacific climate variability in the GFDL Coupled Climate Model, J. Climate, 20, 2434-2451, doi:10.1175/JCLI4133.1, 2007.
Speich, S., Blanke, B., and Cai, W.: Atlantic meridional overturning circulation and the Southern Hemisphere supergyre, Geophys. Res. Lett., 34, 1-5, doi:10.1029/2007GL031583, 2007.

Sprintall, J., Wijffels, S., and Molcard, R.: Direct estimates of the Indonesian Throughflow entering the Indian Ocean : $2004-$ 2006, J. Geophys. Res, 114, 1-19, doi:10.1029/2008JC005257, 2009.

Valsala, V. K. and Ikeda, M.: Pathways and effects of the Indonesian Throughflow water in the Indian Ocean using particle trajectory and tracers in an OGCM, J. Climate, 20, 2994-3017, doi:10.1175/JCLI4167.1, 2007.

Van Sebille, E., Barron, C. N., Biastoch, A., van Leeuwen, P. J., Vossepoel, F. C., and de Ruijter, W. P. M.: Relating Agulhas leakage to the Agulhas Current retroflection location, Ocean Sci., 5, 511-521, doi:10.5194/os-5-511-2009, 2009a.

Van Sebille, E., Biastoch, A., Van Leeuwen, P. J., De Ruijter, W. P. M., Sebille, E. V., Leeuwen, P. J. V., and Ruijter, W. P. M. D.: A weaker Agulhas Current leads to more Agulhas leakage, Geophys. Res. Lett., 36, 10-13, doi:10.1029/2008GL036614, 2009b. van Sebille, E., van Leeuwen, P. J., Biastoch, A., and de Ruijter, W. P.: Flux comparison of Eulerian and Lagrangian estimates of Agulhas leakage: A case study using a numerical model, Deep Sea Res. I, 57, 319-327, doi:10.1016/j.dsr.2009.12.006, 2010.

Wajsowicz, R. C. and Schneider, E. K.: The Indonesian Throughflow's Effect on Global Climate Determined from the COLA Coupled Climate System, J. Climate, 14, 3029-3042, doi:10.1175/1520-0442(2001)014<3029:TITSEO>2.0.CO;2, 2001. 